\title{
Transcending systems thinking in education reform: implications for policy makers and school leaders
}

\author{
Agnieszka Bates
}

Education policy makers in the UK have repeatedly stated their central aim as transforming British education into a 'world class system'. Over the last twenty years, several large scale education reforms have brought radical changes to the school curriculum, teacher professionalism and educational leadership. Explicit in these reforms, is the deployment of measurable standards of pupil attainment as a lever for achieving school improvement. However, despite this proliferation of policies, the claims to educational improvement made by policy makers have been contested. Concerns about the unpredicted and damaging long-term effects of these policies can be linked to the limitations of systems thinking which underpins much of this education reform. A significant flaw of systems thinking is the level of simplification at which policy makers operate on abstract categories such as standards, as if they were reality (Stacey 2010). Based on case study research conducted in two primary schools, this paper suggests that the systemic approach adopted by policy makers may be contributing to an erosion of educational quality and placing potentially damaging expectations on children.

Keywords: systems thinking; standards; quality; public service; education reform

\section{Introduction}

UK education reform has manifested itself in recent years as a proliferation of often disjointed policies referred to as a 'policy epidemic' (Ball 2003, 215) or 'policy hysteria' (Stronach and MacLure 1997). The primary education sector alone has been faced with implementing such major statutory changes to the curriculum and assessment as: National Literacy Strategy (DfEE 1998), National Numeracy Strategy (DfEE 1999), Excellence and Enjoyment: a strategy for primary schools (DfES 2003), Five Year Strategy for Children and Learners (DfES 2004), Every Child Matters (DfES 2004), 
Assessment for Learning Strategy (DCSF 2008). These policies have been viewed as levers for transforming British education into a ‘world-class system' (DfES 2003; DfE 2010). However, the projected targets aimed at raising UK education to 'world class excellence' status in international comparisons, such as the Programme for International Student Assessment (PISA), are as yet to be achieved (Smithers 2007; OECD 2009). Education under the New Labour Governments was criticised as unable to deliver the democratic promise of better life chances for all children (Whitty and Whisby 2009). What has been also contested is policy makers' narrow focus on 'technical-rationality', which reduces the purpose of education to meeting standards and views teaching as a set of skills in delivering instruction (Parker 1997).

Paradoxically, the relentless focus on standards has changed the system in ways that suggest an erosion of educational quality. For example, policy makers' relentless focus on performance indicators created new 'economies of student worth' (Ball 2004, 10), whereby students become viewed as instrumental to producing spectacular outputs (Stronach 2010). Performativity has also unsettled the holistic and humanistic approaches to teacher professionalism (Woods and Jeffrey 2002). New professional identities have emerged, in which the 'caring aspect' has been diminished (Troman 2008). To survive the system, and to avoid naming and shaming (Vulliamy and Webb, 2006), the 'good teacher' complies with, and contributes to, the disciplinary mechanisms that produce a particular version of a 'good school' (Ball, Maguire and Braun 2012, 136). The 'good school' offers normative 'pleasures of performance' to those students who can achieve success or excellence, simultaneously excluding those who cannot. Lastly, the nature of educational governance has changed into what Lawn (2011) terms 'governing through data'. Supported by powerful new technologies and software, 'governing through data' creates a new version of the education system in 
which improvement is equated with more efficient data production and change driven 'by comparison against the past and competitors' (Lawn 2011, 287). These changes sever the connection to education as an inclusive, embodied and moral practice and are indicative of an 'erosion of pedagogic meaning' (Van Manen 1990, 135).

This paper is rooted in complexity thinking (Stacey 2007, 2010) which links these 'unexpected consequences' of UK education policy to the policy makers' technical-rational conception of education as a closed system. Technical-rationality assumes a 'mechanistic' reality where change can be predicted and control centrally maintained through simple cause and effect manipulations. In contrast, complexity thinking (Stacey 2007, 2010) emphasizes non-linearity, unpredictability and dynamic relations in place of 'atomistic' facts. Central to complexity thinking is the notion of complex adaptive systems, such as organisations and other social groupings. As these systems are made up of many agents, they are characterised by complex causality where multiple causes lead to multiple effects. This makes it impossible to predict how these systems will respond and adapt to change over time. Change emerges in these systems as a result of diverse local interactions which invariably include adjustments and resistance to centrally imposed blueprints (Stacey 2007). Stacey's (2010) theory of complex responsive processes of relating views everyday organisational activity as countless iterative processes of communication between actual people. Organisational change is equivalent to changes in the patterns of conversation and is a result of a complex interplay of localised responses to centralised policies. This complexity makes it impossible for policy makers and managers to control the outcomes of reform. Based on a premise that whilst policy makers can select improvement agendas, they are 'unable to choose the responses of others' (Stacey 2010, 214), this paper will argue for transcending systems thinking by recognising the importance of local responses to 
centrally imposed blueprints. In the context of education reform, this would mean seeing education as processes involving people interacting, communicating, making sense of, complying with, as well as resisting policy. The uniqueness and diversity of these processes are overlooked in systems thinking, which reduces educational activity to a set of standardised categories that provide levers for change. The logic of targets and standards may make sense at the abstract level of systemic improvement. However, problems and unpredicted consequences arise when abstraction is mistaken for reality or when resistance is driven out in the effort to shape reality in the exact image of the abstraction. Before discussing these consequences, this paper will first explore the reasons behind the enduring appeal of the abstractions of first order (closed) systems thinking to policy makers, leaders and managers (Stacey 2010). This will provide the focus for the next section.

\section{Systems thinking and technical rationality}

Systems thinking was developed by Von Bertalanffy (1951) around the premise that any kind of system (an organised whole made up of component parts) could be described and explained by means of the same categories and the same formal apparatus (Alhadeff-Jones 2008). The applicability of this formal apparatus to such diverse phenomena as weather systems, the economy, ecosystems, human language and human populations in such diverse knowledge disciplines as cybernetics, evolutionary biology, thermodynamics and economics, contributed to the growing popularity of systems thinking in many areas of activity, including leadership and management, both at the micro and macro levels.

A fundamental distinction in systems thinking is between closed (simple) and complex systems (Stacey 2007; Mason 2008). Examples of the former include the 
clockwork mechanism, the car engine and the central heating system. These systems can be controlled from the outside based on linear causality or simple feedback loops, the purpose of control being system stability. In contrast, in open, complex adaptive systems, which are made up of many components or agents, causality is complex. Since diverse causes lead to multiple effects, it is difficult, if not impossible to predict how these systems will respond and adapt to change over time, as confirmed by the low predictability of weather forecasts, or the emergence and rippling effects of the recent credit crunch (Mackenzie 2008; Kitching et al. 2009). To use an analogy, the fine balance of the forest ecosystem emerges out of complex webs of relationships within the forest itself, such as soil quality, diversity of its plant and animal habitat, as well as through the influence of the environment. Modelling changes in this system over time is a complex task.

The complexity worldview is in stark contrast to the Newtonian-Cartesian epistemology prevalent in contemporary Western thinking (Rorty 1979; Gadamer 1975) and underpinning the scientific method in both natural and social sciences (Elias 1991; Smith and Jenks 2006). Cartesian 'cogito' - 'I think therefore I am' - promotes an analytical, reductive bias in epistemology and, by predicating 'human being-ness' on rationality, prepares the ground for the flourishing of dualistic distinctions between mind and body, thinking and feeling, the knowing subject and the object, the 'implementer' and the 'quality controller'. Newton's metaphysical assumptions and scientific discoveries put forth simplicity and stability, one-to-one relation of cause to effect and a mechanistic view of the world (Mason 2008). Newton's world is a closed system, a mechanism to be manipulated which can be changed by a few powerful individuals.

As Alhadeff-Jones (2008) points out, since the 1970s systems theories have followed two, epistemologically opposed approaches. The first one promotes objective 
techniques for reducing the complexity of the system to the study of its components and their relationships as isolated parts. Referred to as 'first order systems thinking', it presents a paradox of the autonomous system designer or manager, positioned as a knowing, detached observer who controls the system by 'looking at it' and manipulating its components as if from the 'outside', whereas at the same time being part of the system (Stacey 2010). 'Second order systems thinking' seeks to transcend this paradox by acknowledging the constructivist nature of modelling organisations as systems. Recognising multiple subjective realities of people working in organisations enables a shift from 'command-and-control' to more participative approaches to managing organisations. These approaches focus on the processes of construction of shared meanings and on organisational learning. The problem with second order systems thinking, argues Stacey (2010), is that it also presents idealised, prescriptive, albeit less 'mechanical' models, as if they were reality. Both first and second order thinking present a risk of 'getting stuck at the abstract level of systems' and disconnecting from the 'messy' organisational reality (Stacey 2010, 124):

People in organizations do not normally follow the steps proposed by systems practitioners... Instead, the organizational reality is that they engage in daily conversation, gossip, political negotiations, power plays, acts of resistance and pursuit of personal agendas: in short local interaction.

For Stacey $(2010,169)$, transcending systems thinking of both first and second order would be premised on an understanding of human organising in terms of such local interaction, whereby change emerges from a complex interplay of 'deliberate plans and unconsciously motivated actions' and, because of its complexity, is difficult, if not impossible to predict. 
Despite its limitations, first order systems thinking, grounded in the NewtonianCartesian epistemology of technical-rationality, would appear to be in the ascendancy in education policy. This is illustrated by the 'self-improving system' of UK public services which is discussed next.

\section{UK public service 'industries' as self-improving systems}

Government models of Public Service Reform (PSR) are underpinned by systems thinking and, since 2006, have been viewed as self-improving systems (Mead 2006; PSR 2006). The self-improving systems of public services are considered to be made up of four components: Top Down Performance Management, Capability and Capacity, Market Incentives and Users Shaping the Service from Below. The 'self-improving' nature of these systems results from 'incentives for continued improvement and innovation' (PSR 2006, 5) embedded in each of the systems' components. In the education system, top down control is exercised through policy regulation, pupil targets, Office for Standards in Education (Ofsted) inspection, as well as direct intervention 'to tackle failing or underperforming providers' (PSR 2006, 6). Schools' performance, assessed by results in standardised national tests, is published in league tables in order to allow comparisons and inform 'user' choice. The 'users' of the education system, the parents (and presumably the children), can exert bottom-up pressure on schools through funding which follows their choices of schools, so that 'good performers are rewarded and can expand, and poor providers penalised' (PSR 2006, 9). Market incentives encourage schools to compete with one other, whilst Local Authority (LA) control and leadership in individual schools are expected to provide further leverage for raising standards. Potential benefits of the self-improving system can be maximised and potential risks minimised 'if careful attention is paid to getting the detailed design 
conditions right' (PSR 2006, 3). This assumption privileges the simplicity and precision of the design over the complexity of everyday reality of working in schools. The selfimproving system is a closed system and, consequently, ignores the dynamic interplay between diverse local contexts in which schools operate and a multitude of other factors, such as pedagogy, child development and complex relationships that form the fabric of local interaction. The focus on pupil targets and outcomes perpetuates industrial relations, whilst concentrating on standards in Literacy (English) and Numeracy (Mathematics) privileges two curriculum subjects, overlooking the notion of a rich and balanced curriculum.

A similar reduction happens in the micro context of organisations which 'deliver' the services. By viewing individuals functionally, as parts of the organisational whole, first order systems thinking provides abstract models which draw away from contingent situations and everyday local interactions, from what 'really' happens in organisations (Stacey 2010). The level of abstraction in systems thinking disconnects these models from lived experience, privileging abstractions, analysis, categorisation, objectification and mapping, so that:

the ordinary reality of the experience of local interaction between actual human bodies disappeared from view as attention was focused on objectively operating on abstractions as if they were reality. (Stacey 2010, 118)

In the processes of objectifying, measuring, prescribing rules and setting targets, 'real people' are replaced with 'simplified averages' (Stacey 2010, 112).

\section{Managing 'like a state'}


The limitations of first order system thinking (Alhadef-Jones 2008; Stacey 2010) raise a question about the usefulness of technical-rational simplifications of education as a closed system to policy makers. In response, Stacey (2010) points to the paradoxical nature of organisational and social dynamics, predicated on a simultaneous presence of conflicting, self-contradictory ideas that cannot be eliminated or resolved. Stacey draws on the work of Scott $(1998 ; 1990)$ to argue that, paradoxically there would be no state policies for improvement without the activity of abstracting, simplifying and leaving behind real people. Although not a systems theorist, Scott (1998) offers important insights into the potentially flawed applications of systems thinking. In 'Seeing Like a State', Scott explains that simplification, abstraction and mapping are essential tools of modern statecraft. The development of the modern state has been predicated on radically simplified designs for natural and social organisation. This is because simplification...

makes the phenomenon at the center of a field of vision more legible and hence more susceptible to careful measurement and calculation. Combined with similar observations, an overall, aggregate, synoptic view of a selective reality is achieved, making possible a high degree of schematic knowledge, control and manipulation. (Scott 1998, 11)

Although simplification enhances the knowledge and power of state officials necessary for managing change, it can bring about unforeseen and unpredictable consequences in the long term. The development of scientific forestry offers a classic example of this phenomenon. Driven by the desire of the 18th century state to obtain more accurate knowledge of forest revenue, standardised techniques were developed for calculating the yield of commercial timber. These were based on maps and tables that created an 'abstract forest'. Unlike its real-life counterpart, the 'abstract forest' was reduced to 
timber of commercial value with disregard to all other features of the forest ecosystem. As Scott $(1998,15)$ explains, the next logical step was to plant 'well-managed' forests which 'closely resembled the administrative grid':

forest science... backed by state power, had the capacity to transform the real, diverse, and chaotic old-growth forest into a new, more uniform forest... To this end, the underbush was cleared, the number of species was reduced (often to monoculture), and plantings were done simultaneously and in straight rows on large tract... At the limit, the forest itself would not even have to been seen; it could be "read" accurately from the tables and maps in the forester's office.

The logic of standardisation, Scott points out, offers greater possibilities for centralised management, supervision, manipulation and experimentation. It facilitates the development of technical disciplines that can be codified and taught. It also provides ample opportunities for quick economic return. However, it does so at the loss of local diversity, practical wisdom and the impoverishment of local relationships. As it turned out after the second rotation of Norway spruce, the consequences of the conifer monoculture for the new ecosystem were disastrous. Not only did the timber take much longer to grow and was of inferior quality, but the ecology of the system was out of balance, with a much less diverse habitat, unexpectedly huge populations of pests and eroded soil. 'Forest hygiene', developed in response, showed a similar dismissal and lack of understanding of complexity. Although the habitat was still planted with the single crop of Norway spruce, animal species that had disappeared from the monocropped forest were reintroduced by foresters. This created a 'virtual ecology, while denying its chief sustaining condition: diversity' (Scott 1998, 21).

The above is one of a number of historical examples with which Scott illustrates the dangers of the hegemonic planning mentality, when it becomes so fixed on isolating 
simple elements of instrumental value that it dismisses complexity, diversity, tradition, local knowledge and resistance. Centrally designed schemes for social improvement fail when they combine a 'utopian ideology of control and improvement' with 'the unrestrained use of power to achieve the aspirations and when this power blots out the local interaction which could resist or adapt the plans' (Stacey 2010, 105).

Paradoxically, the likelihood of long-term failure increases in inverse proportion to the desire to increase efficiency or maximise profit in the short term:

Utilitarian simplification in the forest was an effective way of maximizing wood production in the short and intermediate terms. Ultimately, however, its emphasis on yield and paper profits, its relatively short time horizon, and, above all, the vast array of consequences it had resolutely bracketed out came back to haunt it. (Scott 1998, 21)

The designer of the standardised forest dismissed the importance of diversity and failed to respect rich relationships that are, because of their complexity, only partly understood. The analogy between the mono-cropped forest and UK education system raises questions concerning the self-improving system designed on the basis of standardisation and efficiency. These questions were investigated through case study research to which we now turn.

\section{Methodology}

A qualitative case study design (Stake 1995) was chosen to analyse and understand the implementation processes at the grass roots of education reform and at the same time to respect the experiences and stories of people engaged in 'their ordinary pursuits and milieus' (Stake 1995, 1). The value of qualitative case study is rooted in research whose function 'is not necessarily to map and conquer the world but to sophisticate the beholding of it' (Stake 1996, 43). 
This article presents findings from an analysis of policy enactment in two UK state primary schools, ‘Abbey Road Primary’ (AP) and ‘Green Lanes Primary’ (GLP). Eighteen semi-structured interviews were conducted with teachers, school leaders, administrative and ancillary staff. Direct observation of staff meetings and numerous teacher-pupil interactions took place over a twelve-month period. By mutual agreement, all the names of places and people have been replaced with pseudonyms. Documents reviewed included twenty two school policies (including Literacy and Numeracy policies) and schemes of work, school Self Evaluation Forms (SEF) and Ofsted inspection reports. Measures have been taken to anonymise all of the texts and material from school websites.

Care has been taken in the data analysis to preserve the complexity and 'wholeness' of the participants, in order to avoid the problems created by abstraction, mapping and categorisation discussed above. However, just like 'statecraft' (Scott 1998), the researcher's craft also relies on abstracting from the world of everyday experience. Consequently, data analysis processes necessarily entail a degree of data reduction and categorisation (Huberman and Miles 1994). Interview data were coded and analysed using NVivo. A thematic approach to data analysis was augmented with description aimed at conveying a sense of 'real' people and places. The patterns and themes which emerged from content analysis were then triangulated with the analytical memos from the observations and with data from the documentary review.

The remainder of this paper outlines the case study findings and discusses the themes which emerged.

The logic of seeing like a state: Grade 2, 'good with many outstanding features' 
Abbey Road Primary (AP) is a three form entry primary school. It is heavily oversubscribed, a sign that Abbey Primary is the preferred choice for more families than the school can accommodate. In the last six years Abbey Primary school expanded from two to three forms, but is still unable to offer places for all applicants. Following an Ofsted inspection in 2007, the school was graded as 'good with many outstanding features'.

Ofsted grades are standardised judgements based on an assessment of how schools provide for pupils' needs. A school can be awarded one of four grades: 'Outstanding', 'Good', 'Satisfactory' and 'Inadequate'. According to Ofsted (2011a), Grade 1 ('Outstanding') means that the school's provision for pupils' needs is 'highly effective' and 'exceptional'. Grade 2 ('Good') judgement means that a school serves its pupils 'well'. A 'Satisfactory', Grade 3 school shows 'reasonable quality', whereas Grade 4 signifies 'Inadequate', or unacceptable standard, which requires significant improvement. Performance in the final year of primary school tests, Year 6 SATs (Standard Assessment Tasks), reported in national league tables, is the ultimate yardstick of schools' provision. Before the inspectors visit a school to spend two to three days observing lessons and interviewing, they scrutinise SATs results, a standardised Self Evaluation Form (SEF) and other statistical data (Ofsted 2011b).

The sub-categories by which a school's overall effectiveness is evaluated include: (a) Achievement and standards; (b) Personal development and well-being of the learners; (c) The quality of provision and (d) Leadership and management (Ofsted 2011a). According to Ofsted Report written following the inspection of Abbey Primary, Grade 2 for the overall effectiveness of the school was arrived at through a standardised mapping, which consisted of grade judgements in each of these sub-categories. The school was judged as Grade 1 in all of the above sub-categories apart from sub-category 
(a), Achievement and standards. Abbey Primary's Ofsted Report emphasised that 'the trend in achievement over the past three years has been variable. In 2005, test results in Year 6 showed a significant dip'.

The remainder of Abbey Primary's Ofsted Report is glowing. As confirmed through data collected in this study, this is an exceptional school. Recent and current parent surveys indicate $98 \%$ satisfaction with the educational experience that the school offers their children. All Abbey teachers give up their time to provide children's afterschool or lunchtime clubs, whereas Abbey pupils are encouraged to contribute to the local community. The school's SATs results have steadily risen above the national and Local Authority average for the last eleven years. Apart from the 'significant dip' in 2005, which influenced Ofsted's overall judgement. Jenny, the Headteacher, recalled her experience of conversations with Ofsted inspectors thus:

...some of them just come in and criticise... a lot depends on the team, it really does. If you've got somebody that's just chanting from a bit of paper... whatever evidence we gave them, they kept chanting the rules...

Working as an inspector means 'seeing like a state', being ruthlessly systematic, efficient and fixated on the synoptic knowledge of a school's performance measured with the national test results. This efficiency, however, is based on a synoptic view so intent on the self-improving system's 'economy of performance' (Stronach 2010), that it fails to register anything outside its narrow focus. As the state privileges the view of its auditors, Ofsted inspectors hold the official power of raising standards, whilst schools merely provide a 'levelled social terrain' (Scott 1998, 5) where the improvement process has been designed to happen. What this means for schools is that the 'techne' of the outsider-spectator, skilled in efficient observation and mapping of 
reality onto the schema of Ofsted criteria, is deemed superior to teachers' perceptions of achievement, their commitment and other dispositions which form the local 'ecology of practice' (Stronach 2010, 65).

The interaction between Abbey teachers and Ofsted inspectors is an example of the potentially damaging effects of abstract performance measures built into the selfimproving system. Ofsted judgement, guided by the dip in SATs, undermined the local articulation of hard work and sense of achievement, without regard to the loss of commitment that this could engender. Paradoxically, however, this 'objective' judgement was subsequently undermined by Jenny and her staff. 'Some of them just come in and criticise' became an organisation-wide pattern of conversation (Stacey 2010) in Abbey Primary, following the inspection. This local response to the inspection resonates with cynicism and resentment as common reactions to Ofsted mechanisms of external judgement and control (Perryman 2009).

\section{A real life system in the image of the design}

Data collected in both schools reveal that the self-improving system does indeed have 'real life' manifestations in both schools. This is apparent in the 'public transcript' which is defined by Scott (1990) as the language that expresses compliance with the official, dominant themes of standards, targets and 'push' on improvement. The analysis of interview transcripts revealed participants' tendency towards 'speaking like the state':

Obviously, we're very driven in terms of targets... (Miriam, Deputy Head, GLP) The overriding improvement has to be on the scores on the doors, SATs... (Eve, Admin Staff, AP)

Whether you like it or not, people make value judgements for our school based on results... (Stephen, Headteacher, GLP) 
Alongside this legitimate, 'public transcript', the 'hidden transcript' was also articulated, in the form of jokes and ironic remarks. For example, Stephen (GLP) joked about how each new Education Secretary introduced change in order to satisfy an ambition to be remembered for 'Baker days... Gove plan...'. Sophie (AP) referred to policy initiatives 'going round in circles, but with a different name each time'. As Scott (1990) explains, 'hidden transcripts' consist of 'offstage' speeches, gestures and practices that contradict and subvert the abstractions imposed by the dominant groups. Despite articulating the voices of the less powerful, 'hidden transcripts' have as much effect on the delivery of public services as the 'public transcript' (Stacey 2010). Alternative values articulated in both schools in defiance of the 'public transcript', suggest that, despite profound changes brought about by the 'policy epidemic', 'other versions of education can still be glimpsed, other rationalities are still being murmured' (Ball, Maguire and Braun 2012, 150).

However, the standards agenda provides a powerful control mechanism regulating the everyday life of the two schools. Interestingly, standards appear to have been embraced not just by the teachers but also by the parents. Despite the choice and voice rhetoric used in the 'self-improving system' document (PSR 2006), parents' aspirations for their children were also framed as academic achievement as measured by SATs:

SATs is one of the measures... It is a measure, but it's not the only one. That's one of the things here that parents like about us - everything else we offer the children... Of course they love the academic - but they like everything else. (Jenny, Headteacher, AP) 
Scott $(1998,345-6)$ argues that the state sees the implementers and recipients of improvement schemes as 'standardised human subjects'. The only 'human subjects' in the model of the self-improving education system are the system's 'Users', reduced to the functions of 'choice' and 'voice'. The system sees teachers in terms of their 'performance' and places enormous demands on schools to perform, beyond raising standards:

...we are now everything to everybody... You sometimes feel like: 'drop them off at six months, pick them up when they're sixteen'... You are responsible for your community, we do a lot of what social services used to do. (Jenny, Headteacher, AP)

Sophie (Deputy Head, AP), who has worked in education since 1971, emphasized unrealistic expectations of solving social problems and the blame schools get:

...the school is seen as the agency that should sort out all the social problems that we have... held more and more accountable for every issue in society... A lot of teachers find it quite distressing sometimes when they get the blame for not getting the best results from a child who comes without breakfast, never does homework, was up till 11 o'clock watching heavens knows what on television.

In the context of constant pressure, the meaning of teaching was articulated as 'doing'. When asked about what teaching means to them, most informants talked about everyday activities of teaching, such as: planning, teaching, monitoring, restructuring, meeting, trying new things, setting direction, role modelling and many more. Performance measures enhance high-modern performativity and give rise to a new kind of school, the performing school (Perryman 2009). This school does not merely perform when under the scrutiny of Ofsted; it seems to present itself as 'active', 'busy', 'never standing still' to other outsiders, for example the researcher. High-modern times appear to privilege ' $I$ 
do therefore I am' over 'I think therefore I am'. In education this results in confusing 'the meaning of teaching or parenting with what we see teachers or parents $d o$ ' (Van Manen 1990, 149) and draws us away from 'real', pedagogically important questions. These questions are posed by Van Manen $(1990,145)$ as: 'What is this situation and action like for the child?' 'What is good and not good for this child?' The more holistic and humanistic purposes of education conceptualised as better life chances for all children are redefined as success in school league tables. As (Stronach 2010, 89) points out, the local metaphors of 'child-centredness' and 'holistic care' are replaced with the global metaphors of 'effectiveness'. As a result...

\footnotetext{
Morality becomes a defective conformity to standards put in place without regard to moral and cultural concerns about what 'education' ought to mean. It becomes an instrument therefore, of efficiency, self-regulation and homogeneity... (Stronach 2010, 35)
}

\section{Thriving or surviving? Métis ${ }^{1}$ and resistance}

Abbey Primary's Ofsted report states that 'children thrive on a diet of good teaching, extremely good relationships and care'. If this is indeed the case, then 'thriving' appears to happen because public service systems manage to deliver a 'good enough' service despite, rather than because of, the 'cult of performance' (Stacey 2010, 208-9). The majority of interviewees accepted the benefits of the first bout of the 'policy epidemic', the National Numeracy and Literacy Strategies (DfEE 1998, 1999). They spoke about the clear structure and progression that the Strategies introduced, as well as the consistency of provision they demanded within individual schools and in the whole system. It is the proliferation of policies that followed that has been problematic. For example, Alice emphasised the piecemeal nature of recent primary policies thus: 
it's very much government led... there's not that progression of consistency. It's 'stop this, do this. Stop this, do this.' (Alice, Deputy Head, AP)

Sophie referred to the proliferation of policies as 'tinkering':

...you've spent a whole year implementing something, and then the government will say 'no'... well they just tinker... if they'd only leave some of us alone to do what we needed to do, we'd get along with it much better... (Sophie, Deputy Head, AP)

When evaluating state improvement schemes Scott $(1998,345)$ accepts that: 'The great majority of them were strongly committed to a more egalitarian society, to meeting the basic needs of its citizens... and to making the amenities of a modern society available to all'. Indeed, at the heart of the self-improving system is an egalitarian vision of 'better public services for all' (PSR 2006, 6). The problematic nature of the education reform scheme is two-fold. Firstly, as Avis $(2009,644)$ argues, the more consensual discourse of recent education policies, articulating support for local decision making, can be interpreted as 'democratic veneer' used for glossing over the continuing domination of centrally determined policy goals. Secondly, centrally controlled schemes can lead to local resistance and, in the longer term, to undesired, unpredicted consequences, both locally and at the level of the whole system. This is because of the narrowness of vision and reduction of diversity in order to facilitate central administration and control (Scott 1998). Some of the undesired consequences of "policy epidemic' noted in both case study schools were the feelings of frustration and concern. Fiona expressed her frustration thus:

It's taken a good few years to implement this... and now it's changing again! (Fiona, Teacher, AP) 
Sophie expressed her concern about professional autonomy and the financial implications of the 'policy epidemic':

I think they [the Government] should take a step back and allow professionals to make the decisions in education. It's not fair to anybody, we put lots of effort into new initiatives and then they are not given enough time to embed and a lot of money, huge amount of money is wasted. (Sophie, Deputy Head, AP)

Every single interviewee expressed frustration with the amount of changes that have been introduced since 1998. What seemed to sustain professionals who 'survive' is 'métis', the practical knowledge and wisdom that arises from everyday experience, a capacity to understand the constantly shifting circumstances and adapt accordingly (Scott 1998). Both the Headteacher and Deputy Head of Green Lanes Primary are appreciated by staff for their wisdom of managing the school 'without putting a lot of pressure on everybody else' (Alison, Teacher). Jenny, the Head of Abbey Primary, has learned from 'life, intuition' that it is impossible to constantly demand people to work hard without rewarding them accordingly and without... 'having a laugh'. Her headship experience, under the governance of many an Education Secretary, has developed her métis of surviving 'policy epidemic':

I never just accept... you've got to be brave and you've got to have the SATs results to back it up. But you can do it, you don't have to say 'we've got to follow this'... When something comes along we don't just say 'Oh dear', we look at it and we say 'okay, what's the best way we can use this for us?' And it's the way we can get round it, the little loopholes, can we cut corners...

Education policy has been employed as a mechanism for controlling professionals who would otherwise enact improvement in their own expert, diverse, often less costly ways. 
In this situation, school leaders are responsible for caring for and supporting their staff (Troman 2008), so as to protect teachers from undue pressures of the 'policy epidemic'.

\section{The price of great expectations}

Since improvement is measured with results in national tests, the demand on teachers to raise them year on year increases pressure on the children they teach. Teachers in both schools talked about the huge amount of time they give to the children in their care; they also set high expectations for them. For the Abbey and Green Lanes children 'to be the best they can be' was frequently repeated in the context of 'achievement', 'attainment levels' and 'targets'. The 'abstract school' is thus attended by 'abstract children' who are expected to make continuous progress to achieve their targets, who work hard and are successful, well behaved, proud to be part of the school, inclusive, respectful, polite, friendly, responsible for their actions, honest. These qualities, cited in both schools, referred to school children between the ages four to eleven, who, in addition, also face varying 'family aspirations'. Improvement was often presented as the Newtonian 'pushing' metaphor: 'pushing results', 'rigour, drive and push'; 'we are always pushing to get to the outstanding criteria'; 'pushing the school forward and not letting it stand still'. The only teachers to talk about fun, excitement and happiness were Early Years teachers, for example Fiona (AP), who also expressed the following concern:

...do you want to push these young children before they're actually meant to, and should you push them? Once you get into education, it goes so fast, you are out so fast, let them be creative, let them be children.

The mechanistic approach was articulated through the 'sausage factory' metaphor. This is illustrated by Eve's point: 
... a bit like a 'sausage factory', in at one end, go out at the other, but that is our job at the end of the day. The children are very individual obviously, but with such a large school there has to be an overriding idea that a lot of stuff is homogenised, I suppose. You know, one size fits all with the majority of the children. (Eve, Admin Staff, AP)

As Jeanne pointed out:

We are a bit of a sausage machine regarding taking exams, life is a bit more rounded than that... (Jeanne, Admin Staff, GLP)

A sense of an industrial system was created by references to targets and constant assessment. Mark (Teacher, AP) raised a concern about the temptation to divert support from the children who have reached the expected target to those who have not:

...we're always assessing the children and there's always a lot of pressure to meet certain targets and results with the children... we seem to always be only a few weeks away from another assessment of the children's learning... if you just do it to meet targets... then to say, those children are on their target so I need not focus on them...

Education system is a public service, but do we understand the meaning and significance of being of service, beyond 'delivering' a service? 'Service' is about work and duty (Oxford English Dictionary 2011) and is etymologically linked to the word 'deserve'. It is thus about an obligation to children who, as recipients of service, deserve 'good' education. An awareness of the deeper obligation of schools was expressed by the Deputy Head of Abbey Primary, Sophie, thus:

We should be sending out children who are confident and who have enjoyed their school experience and want to be in school and have experienced a wide variety of 
activities and found their strengths and areas that they enjoy... who love reading for the sake of it. So we don't want children who are able to do level 5 on a SATs paper but hate reading because they been made to do loads of practice in a way that doesn't engage them or motivate them.

However, in a system which is 'imagined as a series of data flows' (Lawn 2011, 279), paradoxically, children become 'statistics' related to outcomes rather than the recipients of improved education that the system is designed to produce. In this way, the expectation of delivering better education shifts from the system onto the children. As a result, children are no longer viewed as the system's 'users', but as 'data' used to measure the effectiveness of the system.

\section{Being of service in the marketplace}

Built into the design of the self-improving system is an obligation for schools to be 'top' providers in the marketplace, to be 'world-class'. As Sophie emphasised, this has led to 'very bad years for education in this element of competition and in this who's got what from Ofsted and somewhere along the line we seemed to lose the notion of working together and helping each other' (Sophie, Deputy Head, AP). In spite of this, teaching is a vocation for Sophie, Miriam, and for Fiona, who loves teaching Early Years, when 'you're like a second mum to them in a way and the parents are so trusting'. Alice (Deputy Head, AP) spoke of teachers' moral obligation for all children:

our moral obligation really as a teacher is to all children, not just to children in our school. What's best for all children, and do we have a moral view on that? 
There are qualities of care and concern embedded in being of service that not only defy measurement, but are also essential if we are to see the whole child living in the rich web of connections that human beings are in the world.

However, in marketisation and technical-rationality 'gone too far', children are being defined as 'customers' and 'stakeholders'. Following school inspection, Ofsted inspectors are obliged to draft a letter for pupils, 'thanking them for their involvement and providing information about the main outcomes of the inspection' (Ofsted 2011b, 27). These standardised Ofsted letters inform the children of the grades their school has been given, by telling them, for example that they 'attend an excellent school', or that their school's 'overall effectiveness is satisfactory', or, in the case of the inadequate judgement, that 'the inspectors feel that many of you are not making the progress that you are capable of... so we will be checking on your progress very carefully' (Ofsted 2011c). For young children school is a place where they belong, where their friends are, where children from unstable homes find stability and opportunity to grow roots. Ofsted letters, sent to children following inspection, are an intrusion of 'seeing like a state' into the children's world.

To be fully responsible for the service they offer children, educators need autonomy. The underlying professional ethos that emerged from data collected in both schools was that of hard work, commitment and concern for the children in their care. However, these values appeared to exist in tension with the obligations imposed on the schools by the self-improving system's designers and auditors. Through the pressure mechanisms of standards and accountability the system positions professionals in the role of 'servitude' (Osgood 2009, 737), rather than service. Allowing educators more autonomy could resolve this tension and lead to a different kind of school improvement, 
built on the understanding of the child and what is good for the child. Sophie articulated her understanding of the role of education as follows:

...the quality for the children at the end of the day is not just measureable in how many level 4's or GCSEs or whatever those children have got. It's the life experience, it's the kind of person they're going to turn out to be. (Sophie, Deputy Head, AP)

Where the 'cult of performance' presents professionals with a 'hopelessly idealised future and heavy demands for conformity', the result is public service in which 'appearance and presentation replace substance' and 'authentic quality' becomes 'counterfeit quality on the surface' (Stacey 2010, 208). Just as the superficial, spectacular uniformity and order of the standardised forest obscure the loss of a more diverse, natural growth, so the 'good' school's focus on pupil performance grades hides the real meaning of being well educated, summarised by Sophie as 'the kind of person they're going to turn out to be'.

\section{Conclusion}

As a dominant approach to education reform, systems thinking privileges rational planning and control at the top management level over enacting organisational improvement at the grass roots of change. Power inequalities thus established lead to the disconnection between planners and implementers, between abstract blueprints and the 'gritty' reality of change, between the highly esteemed expertise of system designers and lowly rewarded effort of the workforce implementing systemic improvement. Improvement strategies objectify teachers as 'workforce' and children as 'statistics'. The price of the relentless focus on standards is an impoverished educational landscape, in which we lose sight of the whole child and have little time to connect to 
pedagogically important questions about the meaning of teaching and the significance of children in our lives.

Whether it is a dehumanised model of the self-improving system (PSR 2006), or its manifestations in the everyday life of schools, the current state of UK education reflects the problematic nature of 'seeing like a state' and 'doing exactly what the state demands'. Paradoxically, policy makers seem to spend a lot of time at the design board, abstracting and simplifying in an attempt to control the complexity that often defies centralised control. Teachers, on the contrary, have little time to draw away from 'doing', from performing and 'pushing' for targets, in order to reflect and to connect to the core purpose of teaching and caring for children. Scott's (1998) analogy of the 18th century forest reminds us of the limitations of systems thinking and technical-rational approaches. Education as a public service needs be recognised by policy makers and school leaders as a complex phenomenon which cannot be reduced to abstract measures without diminishing the humanness of the children that it has a duty to serve. In the everyday life of a school, being of service signifies a moral obligation to care for and nurture children. It means acknowledging both the advantages and limitations of the synoptic view. In particular, it calls for recognition that 'seeing like a state' can sever our connection to the real life substance upon which the ideas of improvement were based in the first place. Once disconnected, we begin to think and talk about simplified models and systems as if they were reality (Stacey 2010) and, by repeating the 'public transcript' of improvement, sustain its power.

The election of the Coalition Government coincided with the development of a new model of a 'self-improving school system' (Hargreaves 2010, 2011). Written under the aegis of the National College for School Leadership (NCSL) and incorporated into the new NCSL curriculum for training a new generation of school leaders (NCSL 
2011), the model presents a design which is less driven by government intervention, cheaper and more appreciative of local solutions. However, the model seems to be another iteration of a closed system which reduces a school to a 'portfolio of core competences... in how to promote student learning' in order to raise the standards of performance as measured by test results (Hargreaves 2011). Stacey $(2010,115)$ reminds us that 'to think that it is enough to set up an abstract system is to be in constant danger of unpleasant surprises'. As long as a self-improving system is leveraged on targets and the conversation about educational transformation is 'stuck' on this particular version of improvement, the outcomes are unlikely to be transformative. This is because '[s]tuck conversation of a repetitive kind is what stuck unchanging organizations are' (Stacey 2010, 215). Rather than seeking closure and certainty characteristic of the first order systems thinking, an effective policy maker or school leader would be open to paradox and contradiction, to not knowing. He/she would protect local conversations and encourage reflecting on the usefulness of the 'public transcripts' of improvement. This could open up the possibility for the emergence of new meanings and new understanding of educational improvement which the 'policy epidemic' of recent years has effectively closed down.

\section{Notes}

1. 'Métis' (from Greek) denotes a quality combining 'practical wisdom' and 'cunning intelligence'. The concept of 'métis' derives from the Greek mythology and presents an 'array of practical skills and acquired intelligence in responding to a constantly changing natural and human environment' (Scott 1998, 313).

\section{References}


Alhadeff-Jones, M. 2008. Three Generations of Complexity Theories: Nuances and ambiguities.

In Complexity Theory and the Philosophy of Education, ed. M. Mason, 62-78.

Chichester: John Wiley and Sons Ltd.

Avis, J. 2009. Further education in England: the new localism, systems theory and governance.

Journal of Education Policy 24, no. 5: 633-648.

Ball, S.J. 2003. The teacher's soul and the terrors of performativity. Journal of Education Policy 18, no. 2: 215-228.

Ball, S.J. 2004. Education for Sale! The Commodification of Everything? King's Annual Education Lecture 2004. http://mykcl.info/content/1/c6/05/16/42/lecture-ball.pdf.

Ball, S.J., Maguire, M. and Braun, A. 2012. How Schools do Policy: Policy enactments in secondary schools. London and New York: Routledge.

DCSF. 2008. Assessment for Learning Strategy. Nottingham: DCSF Publications.

DfE. 2010. The Importance of Teaching: The Schools White Paper 2010. Norwich: The Stationery Office.

DfEE. 1998. The National Literacy Strategy: Framework for Teaching. London: DfEE.

DfEE. 1999. The National Numeracy Strategy: Framework for Teaching Mathematics. London: DfEE.

DfES. 2003. Excellence and Enjoyment: a strategy for primary schools. London: DfES Publications.

DfES. 2004. Five Year Strategy for Children and Learners. Norwich: The Stationery Office.

DfES. 2004. Every Child Matters: Change for Children. Nottingham: DfES Publications.

Elias, N. 1991. The Symbol Theory. London: Sage Publications.

Gadamer, H.G. 1975 Truth and Method. London: Continuum.

Hargreaves, D.H. 2010. Creating a self-improving school system. Nottingham: National College for Leadership of Schools and Children's Services.

Hargreaves, D.H. 2011. Leading a self-improving school system. Nottingham: National College for School Leadership.

Huberman, A. and Miles, M. 1994. Data management and analysis methods. In Handbook of Qualitative Research, ed. N. Denzin and Y. Lincoln. Thousand Oaks: Sage.

Kitching, J., Blackburn, R., Smallbone, D. and Dixon, S. 2009. Business Strategies and Performance During Difficult Economic Conditions. A Report for the Department of Business Innovation and Skills (BIS). http://www.bis.gov.uk/files/file51879.doc.

Lawn, M. 2011. Governing through Data in English Education. Education Enquiry 2, no. 2 : 277-288.

Mackenzie, D. 2008. Why the financial system is like an ecosystem. http://www.newscientist.com/article/mg20026794.600-why-the-financial-system-islike-an-ecosystem.html. 
Mason, M. 2008. What is Complexity Theory and What are Its Implications for Educational Change? Educational Philosophy and Theory 40, no.1: 35-49.

Mead, S. 2006. Education Reform Lessons from England: An Interview with Sir Michael Barber. http://www.educationsector.org/publications/education-reform-lessons-england.

NCSL. 2011. Licensing leadership development provision: The profession leading the profession. Nottingham: National College for School Leadership.

Ofsted. 2011a. The evaluation schedule for schools: Guidance and grade descriptors for inspecting schools in England under section 5 of the Education Act 2005, from September 2009. Manchester: Crown Copyright.

Ofsted. 2011b. Conducting school inspections: Guidance for inspecting schools in England under section 5 of the Education Act 2005, from September 2009. Manchester: Crown Copyright.

Ofsted. 2011c. Find an Inspection Report. http://www.ofsted.gov.uk/inspection-reports/findinspection-report.

OECD. 2009. OECD Annual Report. http://www.oecd.org/dataoecd/38/39/43125523.pdf.

Osgood, J. 2009. Childcare workforce reform in England and 'the early years professional': a critical discourse analysis. Journal of Education Policy 24, no.6: 733-751.

Oxford English Dictionary, 2011. http://www.oed.com/.

Parker, S. 1997. Reflective Teaching in the Postmodern World: a manifesto for education in postmodernity. Buckingham: Open University Press.

Perryman, J. 2009. Inspection and the fabrication of professional and performative processes. Journal of Education Policy 24, no. 5: 611-631.

PSR. 2006. The UK Government's Approach to Public Service Reform. London: Crown Copyright.

Rorty, R. 1979. Philosophy and the Mirror of Nature. Princeton: Princeton University Press.

Scott, J.C. 1998. Seeing Like a State: How Certain Schemes to Improve the Human Condition Have Failed. New Haven and London: Yale University Press.

Scott, J.C. 1990. Domination and the Arts of Resistance: Hidden Transcripts. New Haven: Yale University Press.

Smith, J. and Jenks, C. 2006. Qualitative Complexity: Ecology, cognitive processes and the reemergence of structures in post-humanist social theory. London and New York: Routledge.

Smithers, A. 2007. Blair's Education: an international perspective. http://suttontrust.com/reports/SuttonTrust_BlairsEd19June.pdf.

Stacey, R.D. 2007. Strategic Management and Organisational Dynamics: The Challenge of Complexity. Harlow: Pearson Education Limited. 
Stacey, R.D. 2010. Complexity and Organisational Reality: Uncertainty and the need to rethink management after the collapse of investment capitalism. London: Routledge.

Stake, R.E. 1995. The Art of Case Study Research. Thousand Oaks: Sage Publications.

Stronach, I. 2010. Globalizing Education, Educating the Local: How method made us mad. London and New York: Routledge.

Stronach, I. and MacLure, M. 1997. Education Research Undone: The Postmodern Embrace. Buckingham: Open University Press.

Troman, G. 2008. Primary teacher identity, commitment and career in performative school cultures. British Educational Research Journal 34, no. 5: 619-633.

Whitty, G. and Wisby, E. 2009. Quality and impact in educational research: Some lessons from England under New Labour. Rotterdam: Sense Publishers.

Woods, P. and Jeffrey, B. 2002. The Reconstruction of Primary Teachers' Identities. British Journal of Sociology of Education, 23, no. 1: 89-106.

Van Manen, M. 1990. Researching Lived Experience: human science for an action sensitive pedagogy. New York: Suny.

Von Bertanalaffy, L. 1951. General Systems Theory: A new approach to unity of science. Baltimore: John Hopkins Press.

Vulliamy, G. and Webb, R. 2006. Education Policy under New Labour. In Changing Teaching and Learning in the Primary School, ed. R. Webb, 9-17. Maidenhead: Open University Press. 